\title{
One Is Not Born A Woman, But Becomes One: Gendered Patterns of Women Subordination in India
}

\author{
Ruman Sutradhar
}

Assam University, Silchar

\begin{abstract}
One is not born a woman, but becomes one" was very correctly put into words by the famous existentialist feminist Simone de Beaviour to explain the gendered patterns of women subordination in society whereby women are assigned the position of „subordinate others". Although gender is the secondary construction of patriarchal society, it is intruded over the natural biological „sex" due to which, men are assumed as the masculine male and women as the feminine female. In the process of gendered construction, men are socialized to dominate because their character is shaped by boldness, roughness and aggressiveness. In contrast, women are socialized to tolerate those dominations, because their character is shaped by softness, shyness and patience. Within the dominant discourses of a patriarchal society like India, gender is internalized by both the sexes through their masculine and feminine traits. This is the reason why women remain submissive throughout their life, sometimes being a traditional good wife who tolerates the tortures inflicted upon her by husband or in-laws in the form of domestic violence and sometimes being an ideal mother who silently accepts the decisions of her son and sometimes as a victim who remain silent even being raped or harassed sexually. These roles are sanctioned socially through various social institutions thereby, glorifying wifehood and motherhood. This paper is an attempt to bring forth the psychological, ideological and cultural bases of this process of naturalization of women subordination in a gendered and patriarchal society like India, where women silently accept their submissive position in state, society and culture.
\end{abstract}

Keywords: Gender subordination, Patriarchy, Domination, Power, Psychological, Ideological

\section{Introduction}

One is not born a woman, or a man, but is made thus. What is that makes a newly born baby to get recognized as a „Woman ${ }^{\text {ee }}$ the subordinate others; or in the other case to get recognized as an individual of the dominant group - men. Is it solely the biological sex that makes the baby to be considered as a girl or a boy? How does the mere vision of the baby's genitals (before or after birth) make one to laugh or weep at an instance? Is it only her sex or something more than that? When does the process begin and how does it affect the lives of women? Why it is at all required to study such cultural formations of gender? These are some of the pertinent questions relating a woman's life. An attempt has therefore been made to seek answers to these questions. For the purpose it would be worthy enough to clarify the terminological issues raised by the theme as conveyed under the present title. Though some of these issues may be obvious, especially to the academicians present here, but it may not be the case otherwise. Also dismissing them would affect the theme"s overall perspective. So, first let us take a look at these issues.

\section{Conceptual Framework: Sex/gender and Masculine/Feminine Dichotomy}

The concepts sex and gender are used by feminist scholars, academicians and researchers worldwide in order to make distinction between the biological and physiological male/female to the socio-cultural man/woman. A woman is assumed to be feminine female; and a man a masculine male, where the terms masculine and feminine indicates one $\mathrm{s}$ gender (socially constructed) held to relate to the two sexes (biological) indicated by the terms male and female. Thus, the feminist concepts of masculinity and femininity are used to signify the social outcomes of being male and female to be understood in terms of the traits that not only describe men and women, but also give men more advantage over women thereby assigning them a subordinate status. Women are defined not by biology, but by their otherness to men (always relative to men). For instance, people feel it easier to call a woman as $\mathrm{A}^{\mathrm{e}} \mathrm{s}$ wife, $\mathrm{B}^{\mathrm{es}} \mathrm{s}$ mother, $\mathrm{C}^{\mathrm{e}} \mathrm{s}$ daughter, $\mathrm{D}^{\mathrm{e}} \mathrm{s}$ sister and the like, and not by her own independent identity. Hence de Beauvoir says, ,man defines woman not in herself but as relative to him...He is the Subject, he is the Absolute- She is the Othere. She however goes on to say that, ,....giving her the means for transcending can enable women to become the „subjects"e (Squires, 1999). To put simply, femininity can be transcended by the deconstruction of gendered norms implicit in ,tradition and culture ${ }^{e e}$. Over the years the women's movement could to a large extent reduce gender gaps between the sexes, but sprawling inequalities still persist between the sexes in the core areas of education, social, economic as well as political which are to its extreme when the women belonging to the marginalized groups like Dalits, immigrants, refugees are taken into consideration. The present study undertakes these core feminist concepts to analyze the gendered patterns of women subordination in India, where subordination is defined as ,the condition of being subordinatee

\section{Bases of women subordination in India}

Indian society is characterized by a hierarchically organized social order based on the principles of subordination, domination and inequality, where the dominant groups are set at the top of hierarchy and the subordinate groups at the bottom either it is in the lines of gender, caste or class. Subordination of women that originated from the unequal distribution of resources (material and mental) has been legitimized by the religious scriptures and is preserved in the society through culture and ideology by which it is psychologically internalized by them, thereby compelling the women to accept their subordinate being in society, which 


\section{International Journal of Science and Research (IJSR) \\ ISSN (Online): 2319-7064}

Index Copernicus Value (2013): 6.14 | Impact Factor (2014): 5.611

remains most prominent in a patriarchal society like India. That is women subordination is the result of this entire sociocultural process of the formation of gender, and this is why it is relevant to have an understanding on the various aspects of gender formation and bases of women subordination.

\section{1. 'It's a girl': Cultural bases of gender formation}

"Although child has an inborn capacity to play but the rules and objects are undoubtedly the product of culture".

Elena Gianini Belotti

In Cvikova, 2003

„It's a girl (or a boy) $)^{\text {ec }}$-these are the first words spelt out after the genital recognition of a baby inside motheres womb (prenatal process) or when the baby open its eyes to see the world. The particular statement makes one to kill the baby or keep it alive; weep or smile; blame the mother or praise her for having given birth to a girl or a boy. Is it only the biological differences of the sexes make one to react so differently at different events? Or, what makes one to go for sex determination tests? It is due to the fact that the simple statement - „It's a girl (or a boy) ${ }^{\text {ee }}$ is not only the baby's sex identification mark but is also its gender identification mark that carries with it the cultural norms of gender, relating the sex of the baby to the traits of femininity or masculinity which gets its obvious representation in selecting names for the baby after birth.

Assigning names to the baby as Jenny or James, Rani or Raja is thus the next step towards the cultural process of gender formation as in most societies name indicates the sex of its bearer and becomes important in gender specific socialization of a child. The child is not given just any kind of a name but a name that clearly denotes its sex (Cvikova, 2003), and hence such cultural identity construct remains close to gender- the concept that is overlapping, correlated and yet distinct from the concept of ,sex ${ }^{e e}$. With its culturally constructed name, the child thus enters the social structure where these constructs become infused with cultural values and in its every step of life the child is socialized to bear the cultural pattern of gender duality that assign the girls with a subordinate position.

As the girl (or boy) steps into the pre-structured cosmos, $\mathrm{s}(\mathrm{he})$ is assigned with the characteristics of sex-typed interests and occupations, appearance, mannerisms, and nonverbal behaviours (Dermott \& Hatemi, 2011), that teach them to accept their subordinate position (or be dominant). Such attribution of gender roles occurs through communication, clothing, selection of toys and games, ways of talking and many more. This is why a girl opt to choose a barbie doll to play not the sophisticated cars, pink as the favorite colour contrasting to the strong blue (as it tends to be soft like a female), or stay inside home to help mother in cooking contrasting to the role of bread earners who work outside (by the traditional division of labour), or choose tailoring or nursing as profession (contrasting to the highly valued jobs of scientists or technocrats). To put in the words of Cvikova, ,the decision between a doll and a car does not follow from the biological sex of the baby but from the social evaluation of the toy as either appropriate or inapposite for a girl or a boy ${ }^{e e}$

In this regard, stereotypical images of women and men play a significant role. For instance, when a boy cries he is told ladkiyon ke jaisa kyun ro raha hai, or if he choose small cooking utensils to play he is said ye kya ladkiyon ka khilona le aya or if he cooks he is laughed at saying, ladki hai kya'. These are some of the very common observations that create a stereotypical image of woman as weak, soft and most important engaged in the household chores which the boys do not and should not do for they are characterized by strong, bold and manly characters of working outside. Such stereotypes emphasizing the division of labour that superiorise men for their role in bread earning are also found in the school textbooks. That is the division of labour between the sexes is socialized not only at home but also in schools and the process that begins from the time of birth is further strengthened by the ideological bases of women subordination.

To illustrate certain pictures from elementary level school textbooks have been collected that contains images of women to be engaged with the household chores like cooking (Figure 1), cleaning utensils (Figure 2) and washing clothes (Figure 3 ) and. Although today there are women athletes, cricketers and wrestlers, all the text book pictures show men as playing those games (Figure 4). In contrast women are shown to play games like hopscotch and kikli (Figure 5). Such stereotypical images of women and men socialize the young kids to follow their mother and father according to the sex. It is thus a very common to find the little girls imitating mother to go to kitchen and little boy to be imitate father (Figure 6)

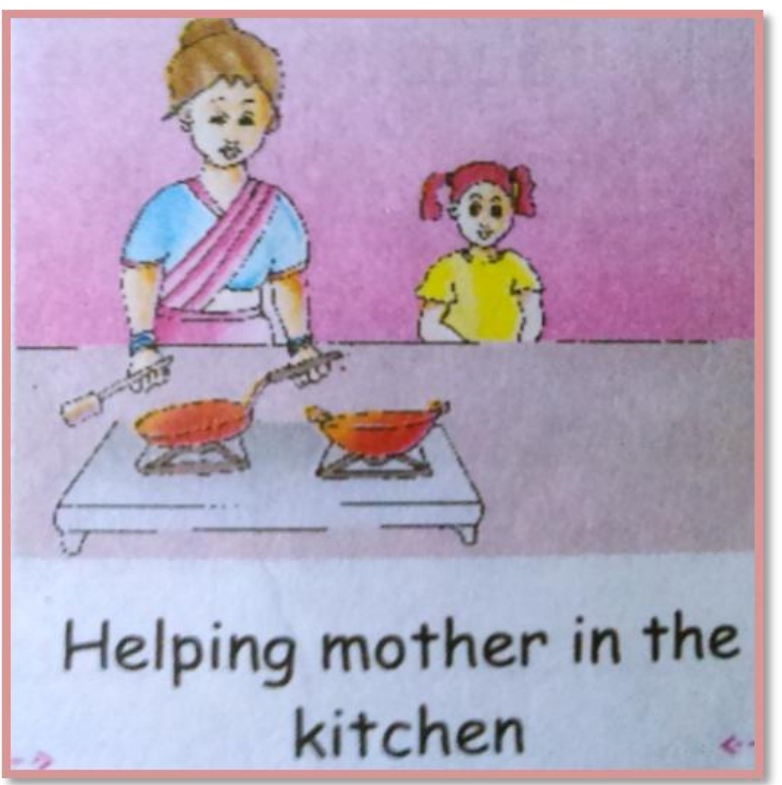

Figure 1: Girl socialized to cook like her mother. 


\section{International Journal of Science and Research (IJSR) \\ ISSN (Online): 2319-7064}

Index Copernicus Value (2013): 6.14 | Impact Factor (2014): 5.611

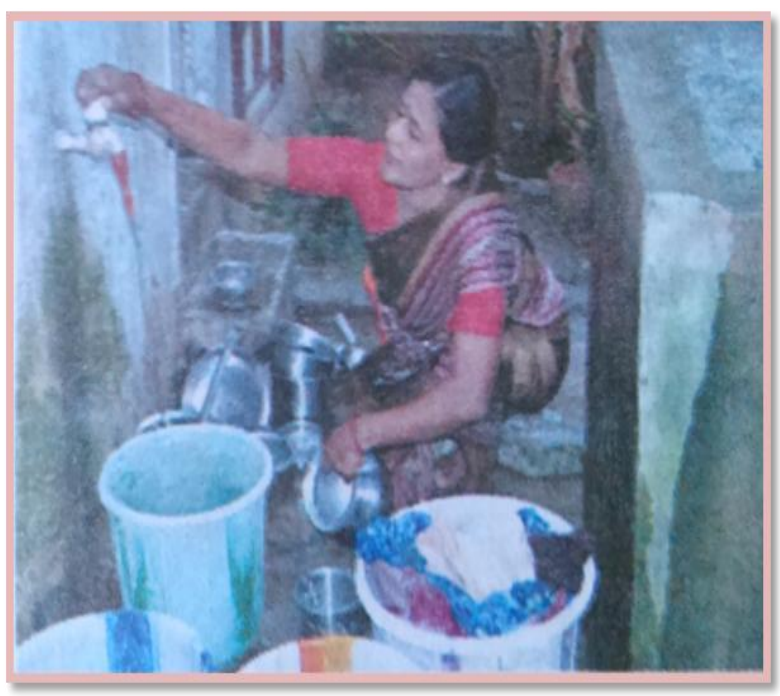

Figure 2: Mother cleaning utensils

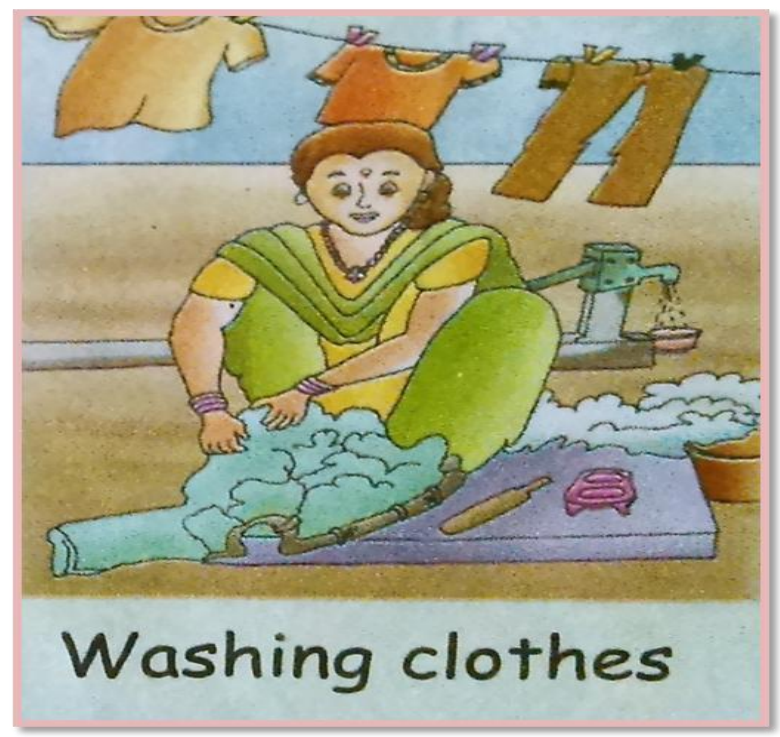

Figure 3: Mother washing clothes

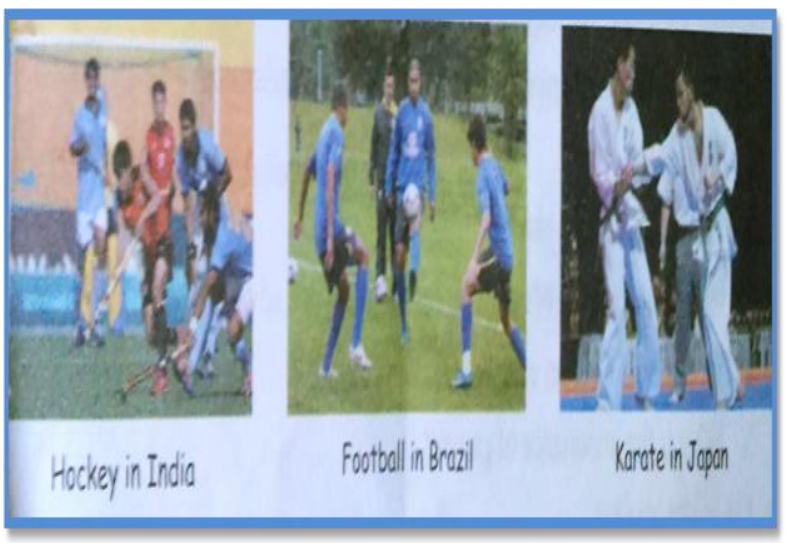

Figure 4: Games meant for boys

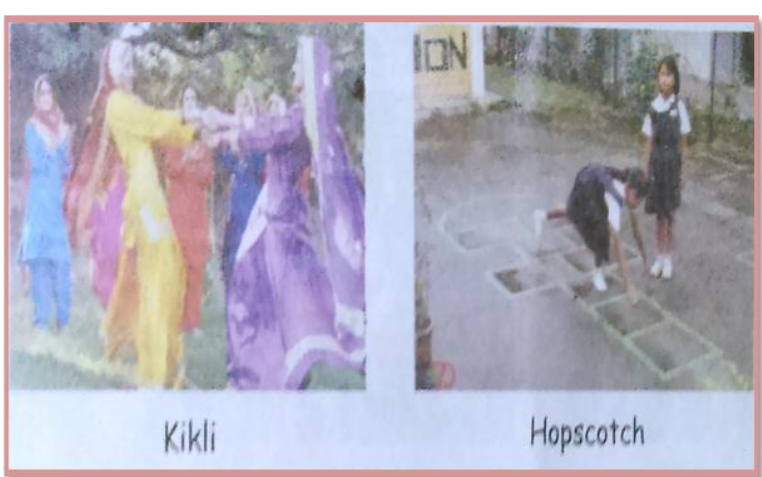

Figure 5: Games played by girls

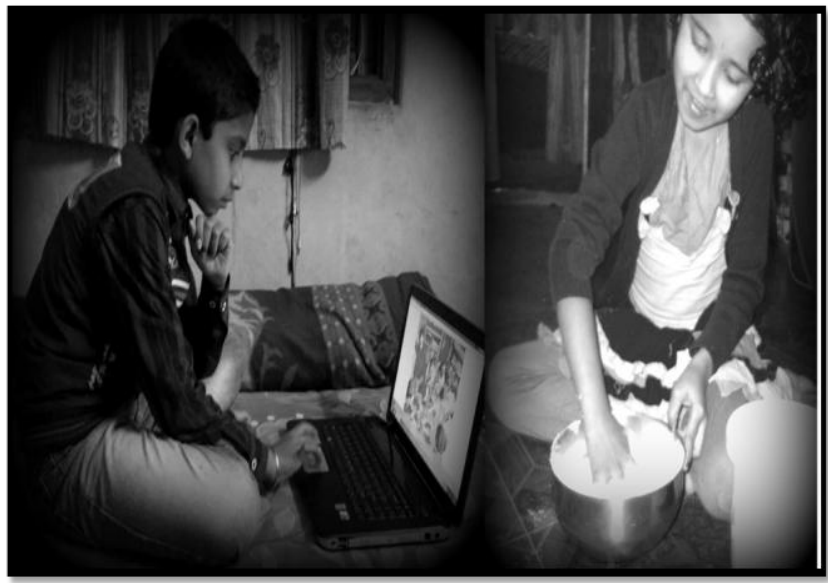

Figure 6: Young kids imitating father and mother

\subsection{Ideological bases of women subordination}

Women enter the category of ,subordinate others ${ }^{\text {ee }}$ through the cultural formations of gendered stereotypes and at the same time internalizes the ideologies emanating basically from religion and the related institutions. This will be analyzed in the light of two ideological Hindu concepts (83 $\%$ of Indian population being the followers of Hinduism), yonishuchita and pativrata that naturalize women's subordination. The Hindu concept of yonishuchita (literally, sexual purity of women) emphasize on the chastity and fidelity of women. Such emphasis clearly reflects two things. On one side, if a girl is asked to have sexual relations with one man (after marriage), she should accept obediently. On the other, it would be taken as a merit if a man can attract more than one woman, while women are supposed to remain a chaste wife throughout her life. The sexually pure women give birth to a legitimate child when the man puts his beej on the kshetra -the field. By sacred tradition woman is declared to be the soil and man as the seed; production of all corporeal beings (takes place) through the union of the soil and the seed (Figure 7). When compared the seed is declared more important because the off springs of all created beings is marked by the characteristics of the seed (Wadley, 1996). 
Female (Kshetra)

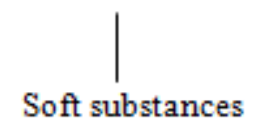

(Unstructured elements of baby)

flesh, skin

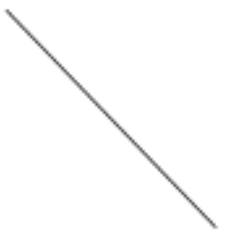

Baby

Figure 7: Hindu metaphor of reproduction

The Hindu metaphor of female-male union thus clarifies two cultural elements of Indian society. One is the superiority of the male beej over female in the process of reproduction as the baby is usually considered to be father's child having fatherly preference in society. The other is that the behavioral characteristics and roles of the baby are reared in accordance with the soft-hard attributes of the kshetra and beej. Therefore when a girl is born she is reared to attain and polish her soft attributes for this will lead her to become an ideal Hindu woman in future, who should not only be sexually pure- the yonishuchit but also a devoted wife-the pativrata. The concept of pativrata (literally, one who is vowed to and fasts for her husband) connotes a wife who has accepted service and devotion to the husband and his family, as her ultimate religion and duty. The pativrata (sati) is the principal feminine model in the religious texts like Manu Dharam Shastra, Ramayana and Mahabharata (Dayal, 2010; Gamberi, 2014), which is opposed to her role as the rakshis (female demons) or alakshmi lasati (dishonoured women). This is the reason why among all the female characters, the dominant norms for a Hindu woman concern her role as a wife (Wadley, 1996) for wife is the benevolent, dutiful and controlled character of woman opposed to the mother who can sometimes be uncontrolled. Such ideals of pativrata have been romanticized through legends, folklore and practices, which will be more clear with some analysis. Hence, the characters of Sita and Savitri are analyzed.

In the great Hindu epic Ramayana, Sita is the virtuous wife of Rama who being a dutiful wife follows her husband to the forest exile. There she is kidnapped by Ravana as she crossed the Lakshman rekha, the demarcation that made her to stay within home or else she will be in danger. Returning back her husband and society questioned her sexual purity and trustworthiness following which Sita gave the agnipariksha by placing herself on a lighted pyre. When she proved her chastity, Sita was accepted by Rama and the entire society. Apart from the story of Ram-Sita, the legend of SavitriSatyavan also has considerable influence on the Hindu women. Alike Sita- the virtuous wife of Rama, Savitri- the virtuous wife of Satyavan also constitute the epitome of a proper wife for Hindu woman. According to the legend of Savitri-Satyavan, Savitri, on the death of her husband went to Yama (God of death) requesting him not to take her husband's life. Yama denied and tried to convince her that all humans have to die one day and that it was impossible to change. But she refused to turn back without the life of her husband. At this, Yama offered her a boon for she was a ,pativrata nari'. Savitri complied this, and asked for sons. Yama agreed to grant her wish but she replied that as a true wife she would have to bear them only by her husband, and no one else. Yama could not change his words and thus Satyavan was saved. Such legends and practices that revolve round their virtue and chastity are slowly internalized by women. And thus, women in India always tend to become an ideal Indian women portrayed as chaste, devout, selfsacrificing and non-complaining. In the process, she herself accepts her subordinate position and becomes the agent of preserving the cultural norms of patriarchy that sanction a subordinate status to the women.

\subsection{Accepting role of 'subordinate others': Psychological bases of women subordination}

Gender formation that begins prior to a child's birth continues in the life of an individual which to its largest extent influence the subordinate group who sometimes remain aware and sometimes unaware of their subordination. They silently accept their subordinate position in society and move on to become the chaste sexually pure women or the yonishuchit and pativrata women because of the gendered process of socialization in a patriarchal society like India that glorifies wifehood by providing norms for women whereby their social roles are restricted to that of wives and mother. In such a society, not a single area can escape the effects of patriarchy which is defined as ,a set of symbols and ideas that make up a culture embodied by everything from the content of everyday conversation to literature and film ${ }^{\text {ee }}$. That is, from the "gendered" masculine and feminine identities of an individual to that of family, work, law and religion, everything is influenced by the effects of patriarchy which is nothing but the subordination and oppression of women (Johnson \& Johnson, 2001).

Patriarchal prescriptions of the masculine and feminine roles remain implicit in the gendered culture which expects certain set of roles and behaviours from men and women in society. These expectations spring from the idea that certain qualities and behaviours are ,natural for women ${ }^{\text {ee }}$ and certain others are ,natural for mene. In the whole process of gender construction, men are socialized to dominate because their character is shaped by boldness, roughness and aggressiveness. In contrast, women are socialized to tolerate those dominations, because their character is shaped by softness, shyness and patience. The social identity of the individuals is framed by these feminine and masculine traits, which are psychologically internalized by both the sexes. This is the reason why women remain submissive throughout their life, sometimes being a traditional good wife who tolerates the tortures inflicted upon her by husband or in-laws in the form of domestic violence and sometimes being an ideal mother who silently accepts the decisions of her son and sometimes as a victim who remain silent even being raped or harassed sexually; thereby silently accepting their subordinate position in state, society and culture.

\section{Volume 4 Issue 11, November 2015}




\section{Conclusion}

Gendered notions existent in a society, especially in a patriarchal society like India place women at a disadvantaged position because at the core of such a society remains gender based discrimination leading to their oppressed and subordinate status. Such discrimination is strengthened by the cultural and ideological bases thereby shaping the female and male psyche to act and be a ,woman" or ,man" with all the feminine and masculine traits that can define their femaleness or maleness and shape the power relations in society which place the males at a higher pedestal. It is this ,gender" that makes a newly born baby to get recognized within the group of ,subordinate others"e, it is not only the sex but the cultural stereotypes of patriarchal notions imbibed within the biological sex of the girl that make one to weep at her birth. The process of social formation of identity that begins prior to a child's birth holds back the growth of the individuals, society as well as nation by denying one category of individual"s equal access to resources. This is the reason why it becomes essential to know the underlying assumptions of gender, because it is due to this gender that ,one is not born but is made a woman"e

\section{References}

[1] J. Cviková, One Is Not Born a Woman or a Man: Sex and Gender, Aspekt, Bratislava, 2003.

[2] J. Squires, Gender in Political Theory, Blackwell Publishers, USA, 1999.

[3] M. Wittig, "One is not born a Woman," in Feminist local and global Theory perspectives Reader, C.R. McCann, \& S.K. Kim (eds.), Routledge, UK, 2013.

[4] P. S. Johnson, \& J. A. Johnson, "The Oppression of Women in India," Sage Publications, 7 (9), pp. 10511068, 2001.

[5] R. McDermott \& P.K. Hatemi, "Distinguishing Sex and Gender," American Political Science Association, 44 (1), pp. 89-92, 2011.

[6] S. Wadley, "Women in Hindu Tradition," in Women in Indian Society, R. Ghadially (ed.), Sage Publications, New Delhi, 1996.

[7] V. Gamberi, "Escaping from Rama: Portraits of Indian women," Culture and Religion: An Interdisciplinary Journal, 15 (3), pp. 354-372, 2014.

Note: This paper has been presented in the International Seminar on "Gender Equality, Power and Violence against Women: Combating Myths and Understanding Legal Provisions", February $13-15$, 2015, conducted at Mahila Mahavidyalaya, BHU. 